Motrivivência $\quad$ v. 26 , n. 43, p. $30-43$, dezembro/2014

http://dx.doi.org/10.5007/2175-8042.2014v26n43p30

\title{
DIRETRIZES CURRICULARES NACIONAIS E SUAS REPERCUSSÕES NOS CURRÍCULOS DE FORMAÇÃO DOCENTE EM EDUCAÇÃO FÍSICA
}

\author{
Fabíola Borel Marques? \\ Zenólia Christina Campos Figueired²
}

\begin{abstract}
RESUMO
Busca investigar de quais modos as Diretrizes Curriculares Nacionais tem repercutido nos currículos de formação de professores de Educação Física para atuar na Educação Básica, bem como a (re)interpretação que o currículo faz dessas diretrizes. Problematiza a formação de professores no País e a formação em Educação Física, a partir da legislação específica que regulamenta os cursos. Trata de um estudo qualitativo, que analisa três documentos curriculares de formação. Identifica formas substancialmente diferentes de repercussão das orientações legais, permite afirmar que essas não representam um engessamento definido para as IES. Os currículos apresentam diferentes e ambíguas formas de interpretação das diretrizes curriculares para os cursos de educação física e confirmam o campo de manobra, omissões, interpretações e materialização de dimensões epistemológicas e políticas, para além daquelas sugeridas nas orientações legais.
\end{abstract}

Palavras-chave: Educação Física; Formação Docente; Diretrizes Curriculares

1 Mestre em Educação Física. UFES. Docente da Rede Municipal de Vila Velha/Espirito Santo, Brasil.

E-mail: fabiolabm@gmail.com

2 Doutora em Educação. Docente Associada do CEFD/UFES, Vila Velha/Espirito Santo, Brasil.

E-mail: zenoliavix@gmail.com 


\section{INTRODUÇÃO}

A inquietação sobre a complexa conjuntura que envolve a formação de professores no Brasil nos levou a investigar de quais modos as Diretrizes Curriculares Nacionais tem repercutido nos currículos de formação de professores de Educação Física, para atuar na Educação Básica, bem como entender a (re)interpretação que o currículo faz dessas diretrizes.

Tomamos como objeto de estudo os currículos prescritos dos cursos de licenciatura em Educação Física das Instituições de Ensino Superior (IES) que oferecem cursos de formação docente em um Estado da região sudeste da federação brasileira, considerando que o currículo prescrito permite "[...] um vasto leque de significações e intenções cruzadas que se colocam em circulação [...] contém ambiguidades, contradições e omissões que criam algum campo de manobra no domínio da interpretação (PARASKEVA, 2008, p. 141)."

Essa compreensão de currículo coloca dúvidas sobre uma determinação quase direta que se tem atribuído às diretrizes curriculares para os cursos de Educação Física, como aquelas exclusivamente responsáveis pelos problemas da formação profissional, não levando em conta dimensões históricas importantes, tais como: que a área possui problemas/desafios no campo epistemológico anteriores a essa legislação ainda não solucionados; que há muito se busca qualificar os cursos para além das determinações legais, lembrando que nem sempre, mesmo na licenciatura plena nos moldes da Resolução 03/87, ${ }^{3}$ obteve-se sucesso ou alcançaram-se as intenções de formação qualificada; que a discussão da formação não deve se pautar, exclusivamente, pelo mercado de trabalho, principal alvo de "ataques" dessa legislação, quando rompe com a viabilidade de uma única formação, nos moldes da antiga licenciatura plena.

Obviamente, não estamos aqui a defender a legislação atual ou a afirmar que seja dispensável de críticas. Reconhecemos a luta das Associações da área educacional, dos professores, pesquisadores e estudiosos que debatem os conflitos políticos e conceituais das políticas de formação docente ${ }^{4}$. Nossa intenção é tão somente desviar um pouco do foco, indicando questões que ajudem a pensar "por dentro" da organização das licenciaturas. Priorizamos abarcar as dimensões entre o prescrito legal e o prescrito constituído/materializado nos currículos dos cursos das IES.

O ponto de partida legal desse estudo são as diretrizes curriculares para os cursos de licenciatura, delimitando-se ao Parecer CNE/CP 009/2001, às Resoluções CNE/CP 01 e 02/2002, e a Resolução CNE/ CP 07, aprovada em 2004. O ponto de chegada são os currículos dos cursos de formação de professores em Educação Física para atuarem na Educação Básica.

3 Resolução do antigo Conselho Federal de Educação (CFE).

4 Consideramos imprescindível, aprofundar e compreender o contexto ideológico e histórico das DCN e por consequência, as críticas, em relação a legislação de formação docente. Dessa forma, sugerimos os estudos de Rocha (2010), Brzezinski (2009), Sarita M. Silva (2006), ANFOPE, ANPED, CEDES (2004), ANFOPE (2001), entre outros. 
$O$ contexto de produção acadêmica do objeto de estudo investigado

Os estudos sobre a política de formação de professores têm sido abordados sob uma perspectiva com enfoque na valorização dos saberes docentes. Essa perspectiva é recente no País, uma vez que suas primeiras discussões datam de 1990 (NUNES, 2001). Parte significativa aponta para a dificuldade em formar um profissional competente e compromissado socialmente. Conforme documento produzido pela Associação Nacional Pela Formação dos Profissionais da Educação (ANFOPE, 2001), o pressuposto fundamental dessa dificuldade é a desconsideração das instituições formadoras de que a docência é a base da identidade profissional do educador, incluindo o distanciamento entre ensino e pesquisa (LÜDKE, 1994)

Nesse mesmo sentido, Brasil (2001, p. 4) destaca "o preparo inadequado dos professores cuja formação, de modo geral, manteve predominantemente um formato tradicional". A formação docente vem atravessando momentos de incertezas, incoerências e expectativas que afetam os sistemas educativos, tais como a chamada crise dos estudos curriculares (PACHECO, 2000) e crise da formação do professor (NÓVOA, 1995; PIMENTA, 1994, 1997, 1999, 2004, 2006; GHEDIN, 2002).

Vivemos um momento de incertezas e dúvidas em que o pressuposto básico é de que passamos por uma "crise" ou "transição" paradigmática no campo da formação docente, da epistemologia e da pedagogia. Não significa banir o que foi construído e/ ou conquistado ao longo da história, nem esquecer ou condenar, trata-se de um debate com novos pontos de vista que redimensionam e atualizam os conhecimentos dos pesquisadores, dos profissionais envolvidos com a docência, da política de formação e dos sistemas educativos.

Neste contexto, a partir da década de 1990, novos enfoques e paradigmas para compreender a prática pedagógica, os saberes docentes e epistemológicos relativos ao conteúdo escolar a ser ensinado/aprendido ganha relevância no campo da formação. Afirma Souza Neto et al (2012, p. 116-117) "que as propostas de formação de professores passaram a enfatizar uma epistemologia da prática na formação". Neste período, inicia-se o desenvolvimento de estudos, considerando a complexidade da prática e dos saberes do professor, destacando a importância de se pensar a formação numa abordagem que vá além da acadêmica ao envolver o desenvolvimento pessoal, profissional e institucional da profissão docente.

Tais demandas exigem não só a reformulação e criação de novas metodologias de ensino, como também de políticas de formação e de instituições formadoras comprometidas e preparadas para a adequação do ensino a essa nova realidade.

Estudar a legislação que regulamenta a formação de professores é buscar a dimensão política da formação desse profissional, especificamente, nesse caso, dos docentes da educação básica. A legislação vigente aponta para a necessidade de que os profissionais formados pelas diversas licenciaturas sejam capazes de repensar e recriar a relação teoria-prática, "[...] o que só pode se dar se tiverem uma formação que permita uma visão globalizante das relações educação sociedade e do papel do educador comprometido com a superação das 
desigualdades existentes" (CONARCFE, 1988 apud BRZEZINSKI, 2009, p. 52) .

Ao se reconhecer a importância da dimensão política da formação docente, há intenção de contextualizar a dimensão Política das políticas oficiais atuais para os Cursos de Licenciatura para a Educação Básica no Brasil, em favor da formação e da valorização dos profissionais da educação. Assim, cabe relatar, segundo Brasil (2001), que, com base em uma análise do contexto educacional nos últimos anos, fez-se a proposta das Diretrizes Curriculares Nacionais para a Formação de Professores da Educação Básica. Essas Diretrizes apresentam encaminhamentos orientadores amplos e normas para uma política de formação de professores, abrangendo sua organização no tempo e no espaço, e para a estruturação dos cursos.

\section{PROCEDIMENTOS METODOLÓGICOS}

O presente estudo foi desenvolvido no Estado do Espírito Santo, região sudeste da federação brasileira, com a perspectiva de pesquisar os currículos prescritos das Instituições de Ensino Superior (IES) que ofertam cursos de licenciatura em Educação Física. Mapeamos o Estado através do portal do Ministério da Educação ${ }^{6}$ e identificamos um universo de $11^{7}$ IES que ofertam cursos de Licenciatura em Educação Física.
Após levantar e organizar os dados referentes ao quantitativo de cursos de licenciatura em Educação Física, de vagas, de carga horária, do tempo de existência e de onde estão localizadas as IES, as informações desses dados foram conferidas com o Coordenador dos Cursos, nas próprias IES. De posse dos dados, cruzamos estes com os critérios traçados para construir e delimitar o perfil do campo de abrangência desta pesquisa.

Os critérios metodológicos definidos foram: oferecer curso de licenciatura em Educação Física em atividade, curso na modalidade presencial, ofertar processo seletivo no período de realização dessa pesquisa, ter pelo menos uma turma formada e estar legalmente registrada e autorizada pelo Ministério da Educação.

Após aplicação dos critérios metodológicos, chegamos ao total de sete cursos, sendo um de IES pública federal e seis de IES privadas. Contatamos, pessoalmente, as sete instituições, mas somente três delas permitiram e assinaram o termo de consentimento para a realização do estudo: uma IES pública federal e duas IES privadas.

Os procedimentos metodológicos de análise dos documentos curriculares das IES constituíram-se, num primeiro momento, pela apresentação descritiva dos cursos; num segundo momento, pela análise propriamente dita, considerando os

5 A sigla CONARCFE corresponde à Comissão Nacional de Reformulação dos Cursos de Formação do Educador. Em 1990, transforma-se em ANFOPE - Associação Nacional Pela Formação dos Profissionais da Educação.

6 O e-MEC é um portal do MEC de Educação Superior do Brasil, onde encontramos Instituições de Educação Superior e Cursos Cadastrados. O e-MEC é um sistema eletrônico de acompanhamento dos processos que regulam a educação superior no Brasil. Todos os pedidos de credenciamento e recredenciamento de instituições de educação superior e de autorização, renovação e reconhecimento de cursos, além dos processos e modificações de processos, serão feitos pelo e-MEC eletronicamente. (EMEC, 2013).

7 Disponível em: < http://emec.mec.gov.br/>. Acesso em: 10 abr. 2013. 
seguintes eixos mapeados nos respectivos documentos legais: I- Eixo articulador dos diferentes âmbitos de conhecimento profissional; II- Eixo articulador da interação e da comunicação, bem como do desenvolvimento da autonomia intelectual e profissional; III- Eixo articulador entre disciplinaridade e interdisciplinaridade; IV- Eixo articulador da formação comum com a formação específica; V- Eixo articulador dos conhecimentos a serem ensinados e dos conhecimentos filosóficos, educacionais e pedagógicos, que fundamentam a ação educativa e VI- Eixo articulador das dimensões teóricas e práticas.

O curso de Licenciatura em Educação Física da IES A, a partir das determinações legais, Resoluções $n^{\circ} 1$ e 2 de 2002 e a Resolução no 7 de 2004 do Conselho Nacional de Educação (CNE), efetivou a mais recente reforma curricular na perspectiva da formação de professores para atuar na Educação Básica no componente curricular específico de Educação Física. O Projeto Pedagógico do Curso (PPC) dessa IES afirma que a identidade profissional encontra-se definida na docência e pautada em uma Educação Física que pode ser compreendida como área que tematiza as práticas corporais em suas dimensões culturais, sociais e biológicas e que se relaciona com as produções culturais que envolvem aspectos lúdicos e estéticos, deixando de ter como foco apenas o esporte ou os exercícios físicos voltados para uma perspectiva restrita de saúde ou performance.
A IES B é uma instituição particular de Ensino Superior tendo iniciado sua trajetória em 1976. No ano de 1999, ofertou o primeiro vestibular para o curso superior de Educação Física, denominado Educação Física, Esporte e Lazer. Surgiu com perspectivas de ampliar a visão e o campo de atuação do profissional da área, mantendo o curso orientado para habilitações no Esporte e Lazer (PROJETO PEDAGÓGICO DE CURSO IES B, 2007).

A IES C é uma instituição particular filantrópica de ensino superior multidisciplinar, entidade civil sem fins lucrativos, com a finalidade de promover e manter obras religiosas, culturais, educacionais, assistências e filantrópicas em benefício da coletividade. Oferece o curso de Educação Física na modalidade de licenciatura, com início de suas atividades acadêmicas no ano de 2000. O curso de Educação Física busca atender com qualidade à crescente demanda da formação educacional superior, oferecendo uma educação que prima pela formação de um cidadão crítico e comprometido com a transformação social em busca de uma sociedade mais justa e igualitária a todos.

\section{ANÁLISE INTERPRETATIVA}

Considerando as orientações legais ${ }^{8}$, retomamos especificamente a legislação na qual são sugeridos pressupostos como critérios para a organização da matriz

8 Do Parecer CNE/CP 009/2001, da Resolução CNE/CP 1/2002 e da Resolução CNE/CP 2/2002 que regulamentam o curso de licenciatura em Educação Física, atribuem condição legal para a autorização de funcionamento e reconhecimento para que as IES ofertem a formação e são referências para a elaboração do Projeto Pedagógico do Curso para formar professores de Educação Física. 
curricular, tempos e espaços do Currículo de Formação de Professores de Educação Física, com fins a desenvolver a análise em busca da compreensão de quais modos as Diretrizes Curriculares Nacionais têm repercutido nos currículos de formação de professores de Educação Física, bem como entender a (re)interpretação que o currículo faz dessas diretrizes.

Como referência para desenvolver essa análise, inspiramo-nos em Sarmento (2003) que orienta as premissas teóricas das abordagens investigativas, na perspectiva interpretativo-crítica, baseadas em pressupostos epistemológicos da singularidade - que busca compreender e/ou interpretar criticamente as singularidades, as diferenças, as infinitas variações dentro de um campo de possibilidades, a emergência do inesperado, o fluido e o ambíguo.

\section{Conhecimentos comuns da Docência}

Analisando o Projeto Pedagógico de Curso de 2007 da IES A, por meio das ementas e programas, identificamos esses conhecimentos nas seguintes disciplinas: Educação Física, Formação Docente e Currículo; Educação Física, Educação e Reflexão Filosófica; Psicologia da Educação; Pensamento Pedagógico da Educação e Educação Física; Política Educacional e Organização da Educação Básica; Didática; Família, Educação Escolar e Sociedade; Fundamentos da Língua Brasileira de Sinais; Educação Física, Aprendizagem e Desenvolvimento Humano; Educação e Inclusão e as unidades curriculares de Atividade Interativa de Formação: Educação Física e Linguagens I e II; Educação Física e Saúde I e II; Educação Física e Programas Sociais I e Il; Educação Física e Cultura Escolar I e II.
Percebemos que há contextualização e discussão das temáticas que envolvem a escola como fenômeno sócio-cultural-educativo, produzido na modernidade; a produção da escola e das práticas escolares; a escolarização da Educação Física no Brasil e suas relações com a área. Propõem e provocam o professor em formação a submeter as práticas educacionais à interrogação filosófica, às peculiaridades do saber filosófico e a sua importância na formação do professor de Educação Física, bem como impulsionam a busca por compreender a relação entre as práticas educativas, as perspectivas filosóficas e as teorias educacionais e da Educação Física. Além disso, os programas problematizam a relação entre diferentes instituições sociais, família e escola, e a inter-relação da prática educacional escolar com outras práticas sociais.

Esses conhecimentos comuns da docência, no currículo da IES B ganham outro formato. Identificamos aproximações da discussão docente nas disciplinas Bases Pedagógicas da Educação; Psicologia da Educação Física; Educação Física, Diversidade e Inclusão; Avaliação Educacional; Didática da Educação Física; e Libras. Na análise dos programas dessas disciplinas e especificamente das ementas e objetivos, compreendemos que estão fundamentados o pensamento pedagógico e avaliativo produzido no contexto dos movimentos sócio-históricos, políticos e culturais da história da educação e suas implicações com a prática pedagógica; as teorias da psicologia e suas abordagens acerca do corpo e do movimento com possibilidades de aplicação no processo educacional e método de ensino.

$\mathrm{Na}$ terceira instituição, IES C a docência é abordada por meio das disciplinas: 
História da Educação Brasileira; Produção de Texto; Psicologia da Educação; Educação e Diversidade Humana; Didática Geral; Filosofia da Educação; Produção do Conhecimento no Espaço Profissional; Políticas Públicas e Legislação Educacional; Socioantropologia da Educação; Produção do Conhecimento Pedagógico; Estrutura e Estudos em Currículo; Ética e Formação Humana; Língua Brasileira de Sinais e Práxis das Africanidades Brasileiras. A instituição formadora elegeu essas unidades curriculares para sistematizar e promover um diálogo pedagógico entre os conhecimentos filosóficos, educacionais e pedagógicos que baseiam a ação do futuro professor. Esses conhecimentos são articulados e significados no sentido de pensar possibilidades educacionais no exercício do magistério em Educação Física na Educação Básica, conforme descrito nas ementas.

\section{Conhecimentos das Dimensões Teóricas e Práticas e os Conhecimentos da Pesquisa na Docência}

Debruçamo-nos, especificamente, sobre a materialização das dimensões teóricas e práticas e a pesquisa. Imbricado a esta temática, dialoga e articula o Estágio Supervisionado como um espaço de mediação capaz de proporcionar os vínculos necessários entre a docência e o exercício da profissionalidade docente, potencializando a reflexão teórica-prática da formação e as práticas de ensino (SOUZA NETO, 2012). O estágio é obrigatório e deve ser vivenciado ao longo de todo o curso, desde o primeiro ano de formação, e, ao final, efetivar a docência compartilhada, sob a supervisão da escola de formação, bem como envolver uma atuação coletiva de todos os formadores.

$\mathrm{Na}$ IES A, a pesquisa e os conhecimentos das dimensões teóricas e práticas na docência são tratados nas seguintes unidades curriculares: Pesquisa e Docência em Educação Física; Trabalho de Conclusão de Curso I; Trabalho de Conclusão de Curso Il; Ensino da Educação Física na Educação Infantil; Ensino da Educação Física no Ensino Fundamental I; Ensino da Educação Física no Ensino Fundamental II e Ensino da Educação Física no Ensino Médio; Seminários Articuladores de Conhecimentos; Estágio Supervisionado da Educação Física na Educação Infantil; Estágio Supervisionado da Educação Física no Ensino Fundamental I; Estágio Supervisionado da Educação Física no Ensino Fundamental Il e Estágio Supervisionado da Educação Física no Ensino Médio. A forma como a instituição formadora A significa e materializa os conhecimentos nesse eixo possibilita o preparo da inserção do futuro professor na Educação Básica por vincular a formação inicial com a realidade escolar. (PIMENTA, 2006 e PIMENTA; LIMA, 2008).

O modo como se efetiva a materialização desses conhecimentos no currículo apresenta algumas particularidades. A organização do estágio supervisionado está imbricada e articulada com o ensino da Educação Física e envolvem questões como a investigação e intervenção no ambiente escolar. Visualizamos essa premissa na articulação do tempo/período e conhecimento. As disciplinas de Estágio Supervisionado da Educação Física na Educação Infantil são pensadas e alocadas ao mesmo tempo/ período que a disciplina de Educação Física na Educação Infantil e, sucessivamente, as demais unidades curriculares de Estágio e 
Ensino da Educação Física abarcando todas as etapas da Educação Básica.

Na IES B os conhecimentos das dimensões teóricas e práticas e conhecimentos da pesquisa repercutem no currículo por meio das disciplinas Metodologia Científico, Estágio Supervisionado Escolar em Educação Física I, Estágio Supervisionado Escolar em Educação Física II, Estágio Supervisionado Escolar em Educação Física III e Estágio Supervisionado Escolar em Educação Física IV. Observamos que a instituição formadora materializa disciplinas que tratam conhecimentos sobre metodologias para pesquisa científica, pesquisa, vivência e prática inseridas no espaço profissional escolar. O currículo da instituição formadora apresenta uma maneira diferente para organizar esses conhecimentos. Podemos afirmar que a articulação entre os conhecimentos das dimensões teóricas e práticas e os conhecimentos da pesquisa na docência são 'flexibilizados'. Ao que parece os conhecimentos da pesquisa não estão focados na docência, mas de modo a atender as diversas áreas de atuação da Educação Física. No PPC, afirma-se, por exemplo, o conceito de "empreendedorismo, entendido como a oferta de educação capaz de associar os conhecimentos que promovem as necessidades e demandas de trabalhos identificadas na sociedade."

Observamos, também, um modo diferente de materializar o Estágio Supervisionado nas unidades curriculares. Nas disciplinas Estágio Supervisionado Escolar em Educação Física I, II e III, o currículo efetiva a inserção no cotidiano escolar, efetivamente na educação infantil e no ensino fundamental I e II, respectivamente. Já na unidade curricular, Estágio Supervisionado Escolar em Educação Física IV, a instituição destina essa disciplina para finalizar a construção dos relatórios das práxis pedagógicas vivenciadas nos Estágios das unidades anteriores I, II e III, problematizadas e registradas essas experiências nos portfólios.

$\mathrm{Na}$ IES C, os conhecimentos das dimensões teóricas e práticas e conhecimentos da pesquisa na docência encontra-se sistematizada nas disciplinas Fundamento e Metodologia da Ciência; Oficina I, II, III e IV; Seminário de Monografia I; Seminário de Monografia II; Estágio Supervisionado I, II, III e IV. A pesquisa se apresenta materializada com ênfase diferenciada no currículo de formação docente da instituição C. Para tanto, na disciplina de Fundamento e Metodologia da Ciência, a IES C demonstra a intenção de trabalhar a compreensão da "relação entre produção do conhecimento e método científico e reconhecer a importância da pesquisa para o desenvolvimento acadêmico/formação docente".

Em relação ao Estágio Supervisionado, a IES C apresenta um modo singular para materializar essas unidades no currículo de formação. Como mencionado neste estudo, no item Síntese Descritiva do Projeto Pedagógico do Curso, a singularidade está baseada na possibilidade do Estágio Supervisionado ser realizado fora do município em que o acadêmico estuda. Assim, ele faz o curso em um município e pode cumprir 
o estágio em outro, com duas justificativas: a de que onde a instituição se localiza não tem escolas de Educação Básica em quantidade que possa comportar o número de estagiários e de que a maioria dos acadêmicos mora em outros municípios.

\section{Conhecimentos da Formação Comum e da Formação Específica}

$\mathrm{Na}$ IES A, as dimensões que envolvem os conhecimentos da formação comum e da formação específica no currículo materializam-se nas disciplinas obrigatórias: Educação Física e escola; Corpo, Movimento e Conhecimentos Biológicos; Comportamento Motor; Corpo, Movimento e Conhecimentos Bioquímicos e Nutricionais; Corpo, Movimento e Conhecimentos Anatômicos e Cinesiológicos; Corpo, Movimento e Conhecimentos Fisiológicos; Introdução à Educação Física; Educação Física, Corpo e Movimento; Educação Física, Aprendizagem e Desenvolvimento Humano; Corpo, Movimento e Escolarização; Conhecimento e Metodologia do Ensino da Dança; Ensino da Educação Física na Educação Infantil; Conhecimento e Metodologia do Ensino da Ginástica; Conhecimento e Metodologia do Ensino do Jogo; Ensino da Educação Física no Ensino Fundamental I; Ensino da Educação Física no Ensino Fundamental II; Educação Física, Adaptação e Inclusão; Conhecimento e Metodologia do Ensino dos Esportes Individuais; Conhecimento e Metodologia do Ensino dos Esportes coletivos; Ensino da Educação Física no Ensino Médio; Epistemologia da Educação Física; Educação Física, Educação e Escolarização.

A IES A efetiva esses pressupostos no currículo de formação, abordando os conhecimentos científicos básicos sobre a dimensão biológica do corpo humano e dos movimentos corporais, da cultura brasileira e da avaliação dos movimentos. Para tratar desses conhecimentos, a instituição formadora alocou no curso a disciplina Educação Física e Escola na perspectiva de articular e discutir as relações e implicações desses conhecimentos, como elementos norteadores dos processos de legitimação da Educação Física no currículo escolar, na prática pedagógica e nos procedimentos de ensino no contexto da Educação Básica. Desse modo, a IES A articula as dimensões dos conhecimentos científicos para significá-los na prática pedagógica dos professores de Educação Física. Os conhecimentos específicos de cunho técnico-instrumental e de metodologias expressam as dimensões teóricas e práticas do ensino da Educação Física no currículo com enfoque na Cultura Corporal de Movimento, dos fenômenos sócio-histórico-cultural. São pensados, discutidos e significados como forma de construção, vivência, experimentação e problematização no processo de transposição didática, mediando a transformação desses conhecimentos em objeto de ensino para a Educação Básica. Dessa forma, o currículo prescrito de formação da IES A é claro e coerente no que se propõe: formar licenciados em Educação Física.

A IES B, trata os conhecimentos da formação comum e da formação específica por meio das disciplinas Aprendizagem e Desenvolvimento Motor; Recreação; Bases Filosóficas das Atividades Corporais e Esportivas; Bases Sociológicas das Atividades Corporais; Introdução à Educação Física; Anatomia Humana; Futebol; Metodologia da Dança e Expressão Corporal; História da Educação Física e do Esporte; Atletismo; Metodologia 
da Cultura Popular; Metodologia das Lutas; Pensamento Pedagógico da Educação Física; Teoria e Prática do Lazer I; Basquetebol; Handebol; Voleibol; Metodologia dos Esportes Coletivos I e II; Teoria e Prática do Lazer II; Educação Física na Educação Básica; Metodologia dos Esportes Individuais; Natação; Ginástica Artística; Ginástica Rítmica; Educação Física para Grupos com Necessidades Especiais; Legislação e Ética nas Atividades corporais; Psicologia Aplicada à EF, esportes e Lazer; Educação Física, Infância e Adolescência e Empreendedorismo.

Nesse contexto, a IES B sinaliza que o curso procura atender as demandas do mercado de trabalho na área, trata o conhecimento sob diferentes aspectos e com enfoque próprio em que se reflete a questão da busca de formar profissionais empreendedores e preparados para atuar em vários campos de intervenção na área. Assim, é perceptível que a matriz curricular materializa uma formação profissional que possa abarcar todos os campos de intervenções da área da Educação Física e não efetiva uma formação com base na identidade docente.

A IES C aborda os conhecimentos da formação comum e da formação específica nas disciplinas obrigatórias Biologia Celular e Histologia; Anatomia Humana; Fisiologia Humana; Crescimento e Desenvolvimento I; Crescimento e Desenvolvimento II; Fisiologia do Exercício; Cinesiologia; Nutrição e Educação Física; Primeiros Socorros e Emergências em Educação Física e Esportes; Metodologia do Ensino da Educação Física; Práxis dos esportes individuais I; Práxis dos Esportes Individuais II; Práxis dos Esportes Coletivos I; Práxis dos Esportes Coletivos II; Práxis da Dança; Práxis das lutas e Futsal; Práxis do Lazer; Práxis dos Jogos; Práxis dos Esportes de Aventura; Práxis da Ginástica;
Práxis dos Esportes de Areia; Práxis dos Esportes de Raquete; Educação Física Adaptada e Fundamentos da Educação Física e Organização de eventos em Educação Física. E nas disciplinas optativas, a saber, Ambiente Educação e Saúde; Temas atuais em Educação Física; Práxis das Atividades Aquáticas; Práxis Ginástica laboral e ergonomia; Práxis da Ginástica em academia; Práxis dos Esportes de Areia; Práxis dos Esportes de Raquete; Práxis da Musculação; Atividades Física para grupos especiais; Saúde Coletiva e Epidemiologia e Atividade Física e envelhecimento.

As demais disciplinas, desse eixo, tratam dos conhecimentos da formação específica com a intenção de materializar os saberes metodológicos e técnico-instrumental e as dimensões teórico-metodológicas norteando o trabalho em Educação Física. $\mathrm{Na}$ sua interface com o campo da didática na formação de professores, trata os conhecimentos dos esportes, lutas, dança, jogos e ginásticas sob os aspectos sócio-histórico-cultural, técnico e pedagógico, vivenciando e/ou ressignificado os movimentos do corpo e suas possibilidades criativas em aulas de Educação Física escolar. Trata, ainda, do planejamento, da organização, da realização e da avaliação nos diferentes campos de intervenção educativa, no ensino formal e não- formal.

\section{CONSIDERAÇÕES FINAIS}

O processo analítico dos documentos curriculares dos cursos de formação docente em educação física foi desenvolvido a partir dos principais pressupostos da legislação: conhecimentos comuns da docência, conhecimentos das dimensões teóricas e 
práticas e os conhecimentos da pesquisa na docência e os conhecimentos da formação comum e da formação específica.

A análise dos três currículos de formação permite afirmar que as orientações curriculares nacionais não representam um engessamento definido para as IES, por vezes, dito e reproduzido por estudiosos da área. Os currículos analisados apresentaram diferentes e ambíguas formas de interpretação das diretrizes curriculares para os cursos de educação física e confirmam o campo de manobra, omissões, interpretações e materialização de dimensões epistemológicas e políticas, para além daquelas sugeridas nas orientações legais.

Os currículos prescritos dos cursos de licenciatura em Educação Física das IES A, IES B e IES C, efetivam de forma clara, diferentes modos de interpretar e materializar a legislação docente e a legislação referente a área, existindo uma diferença entre os pressupostos prescritos legais e os pressupostos prescritos construídos nos currículos dos cursos. São três modos de materializar a formação de licenciatura em Educação Física, três modos diferentes de repercussão das diretrizes curriculares.

$\mathrm{Na}$ IES A, materializa-se a identidade docente como base na formação de professores, o currículo é licenciatura em Educação Física para atender a Educação Básica e o curso integraliza-se em quatro anos. A IES B, materializa um perfil confuso de identidade profissional, o curriculo é generalista com orientação instrumental técnico e empreendedor. O curso da IES B habilita em licenciatura e bacharelado em um formato concomitante, no mesmo espaço e tempo, no período quatro anos. A IES C apesar de o curriculo estar voltado para formar professores de Educação Física, efetiva a habilitação em licenciatura e também as habilitações de licenciatura e bacharelado. Sendo que o bacharelado é ofertado, após o término da docência, no prazo de um ano, significando que o curso de bacharelado é realizado com o formato de complementação do curso de Licenciatura em Educação Física. Essa IES materializa duas habilitações no mesmo espaço e tempo, em um prazo de quatro anos e seis meses, estudando no turno noturno, ou quatro anos, se o discente estudar no turno vespertino.

\section{REFERÊNCIAS}

ANFOPE. Associação Nacional pela Formação dos Profissionais da Educação. Análise da Versão Preliminar da Proposta de Diretrizes para a Formação Inicial de Professores da Educação Básica, Em Curso De Nível Superior. Documento para subsidiar discussão na Audiência Pública Regional, Recife, 2001. Disponível em: < http://portal. mec.gov.br/cne/arquivos/pdf/Recife. pdf $>$. Acesso em: 10 abr. 2012.

ANFOPE; ANPEd; CEDES. A definição das diretrizes para o curso de pedagogia. Documento enviado ao Conselho Nacional de Educação visando a elaboração das Diretrizes Curriculares Nacionais para os Cursos de Pedagogia, em 10.09.2004. Disponível em: < http:// www.anped.org.br/200904posicaodiretr izescursospedagogia.doc > Acesso em: 11 abr.2012.

BRASIL. Conselho Federal de Educação. Resolução n 3 de 16 de junho de 1987. Dispõe sobre os mínimos de conteúdos e duração a serem observados nos cursos de graduação em Educação 
Física (bacharelado e/ou licenciatura). Diário Oficial, (172), Brasília, Set. 1987. BRASIL. Conselho Federal de Educação. Ministério da Educação. Conselho Nacional de Educação, Parecer CNE/ CP n. 009/2001, de 8-05-2001: institui as diretrizes curriculares nacionais para a formação de professores da educação básica, em nível superior, curso de licenciatura, de graduação plena. Brasília, 2001. . Resolução CNE/CP 1, de 18-022002: institui as diretrizes curriculares nacionais para a formação de professores da educação básica, em nível superior, curso de licenciatura, de graduação plena. Brasília, 2002.

Resolução CNE/CP 2, de 19-02-2002: institui a duração e carga horária dos cursos de licenciatura, de graduação plena, de formação de professores da educação básica em nível superior. Brasília, 2002.

. Parecer CNE/CES n. 0058, de 18-022004: institui as diretrizes curriculares nacionais para os cursos de graduação em educação física, em nível superior de graduação plena. Brasília, 2004.

. Resolução CNE/CES n. 7, de 31-032004: institui as diretrizes curriculares nacionais para os cursos de graduação em educação física, em nível superior de graduação plena. Brasília, 2004.

BRZEZINSKI, I. Pesquisa sobre formação de profissionais da educação no GT 8/Anped: travessia histórica. Revista Brasileira de Pesquisa sobre Formação de Professores, v. 1, p. 1-5, 2009.

LÜDKE, M. Avaliação institucional: formação de docentes para o ensino fundamental e médio (as licenciaturas). In: Série: Cadernos CRUB, v. 1, n. 4, Brasília, 1994.
A complexa relação entre o professor e a pesquisa. In: André, M. (Org.). O papel da pesquisa na formação e na prática dos professores. Campinas: Papirus. 2001.

NÓvOA, A. Os Professores e a sua Formação. 2. ed. In: GÓMES, Angel Pérez. O Pensamento Prático do Professor: a formação do professor como profissional reflexivo. (Trad.). Graça Cunha et al. Lisboa: Publicações Dom Quixote Instituto de Inovação Educacional. 1995.

. Os professores e as histórias da sua vida. In: NÓVOA, A. (Org.). Vidas de professores. Porto: Porto Editora, 1995. NUNES, C. M. F. Saberes docentes e formação de professores: um breve panorama da pesquisa brasileira. Revista Educação e Sociedade, Campinas, ano XXII, v. 74, p. 2742, abr. 2001.

NUNES, M. L. F. Frankenstein, monstros e

Ben 10: fragmentos da formação inicial em Educação Física. 2011. 287 f. Tese (Doutorado em Educação) - Faculdade de Educação, Universidade de São Paulo, São Paulo, 2011.

PACHECO, José Augusto. Territorizar o currículo através de projectos integrados. In: Pacheco, J. (org.) Políticas de Integração Curricular. Porto: Porto Editora, 2000.

PARASKEVA, J.M. Educação e Poder. Abordagem críticas e pós-estruturas, Portugal: Edições Pedago, 2008.

PIMENTA, S. G. O estágio na formação de professores - unidade teoria e prática? São Paulo: Cortez, 1994.

. Para uma re-significação da Didática - ciências da educação, pedagogia e didática. (uma revisão conceitual e uma síntese provisória). In: Pimenta, 
S G. (org). Didática e Formação de Professores - percursos e perspectivas no Brasil e em Portugal. São Paulo: Cortez, 1997.

. Formação de professores: Identidade e saberes da docência. In: PIMENTA, S.G. (Org.) Saberes pedagógicos e atividade docente. São Paulo: Cortez, 1999.

Professor pesquisador: mitos e possibilidades. Trabalho apresentado no XII Encontro Nacional de Didática e Prática de Ensino, Curitiba, 2004.

.Professor reflexivo: construindo uma crítica. In: PIMENTA, S.G. e GHEDIN, E. (Orgs.). Professor reflexivo no Brasil: gênese e crítica de um conceito. 4. ed. São Paulo: Cortez, 2006.

PIMENTA, S. G.; GARRIDO, E.; MOURA, M. O.; PENTEADO, H. D. O. Qualificação do ensino público e formação de professores. Pro-Posições (Unicamp), Campinas - SP, v. 11, n. 1 (31), p. 56-69, 2000.

PIMENTA, S. G. e GHEDIN, E. (orgs.). Professor reflexivo no Brasil: gênese e crítica de um conceito. São Paulo: Cortez, 2002.

PIMENTA, S. G.; LIMA, M. S. L. Estágio e docência. 3. ed. São Paulo: Cortez, 2008.

SILVA, S. M. Diretrizes curriculares nacionais e a formação de professores: flexibilização e autonomia. Campinas UNICAMP, 2006 (tese).

SARMENTO, M. O estudo de caso etnográfico em educação. In: ZAGO, N.; CARVALHO, M. P.; VILELA, R. A. T. Itinerários de pesquisa: perspectivas qualitativas em sociologia da educação. Rio de Janeiro: DP\&A; 2003a. p. 137-179.

SOUZA NETO, S. et al. O estágio supervisionado como prática profissional, área de conhecimento e locus de construção da identidade do professor de educação Física. In: NASCIMENTO, J. V.; FARIAS, G. O. (Orgs.). Construção da identidade profissional em educação física: da formação à intervenção. Florianópolis: Editora da UDESC, 2012, p. 113-140. 
NACIONAL CURICULARES DIRECTIVES AND IMPLICATIONS OF CURRICULUM IN PHYSICAL EDUCATION TEACHER FORMATION

\begin{abstract}
Search investigate what modes the National Curriculum Directives have passed on curricula for formation physical education teachers to work in primary and secondary education, and the (re)interpretation that the curriculum makes these directives. Discusses the formation of teachers in nation and formation in Physical Education from the specific legislation that regulates the courses. Is a qualitative study that analyzes three formation curriculum documents. Identifies substantially different forms of repercussion of legal orientations, allows to affirm that these do not represent an immobilization defined for Institution of Higher Education. Curricula exhibit different shapes and ambiguous interpretation of curriculum directives for physical education courses and confirm the field maneuver, omissions, and interpretations materialization of epistemological and political dimensions, beyond those suggested in the legal orientations.
\end{abstract}

Keywords: Physical Education; Teacher Formation; Curriculum Directives

\title{
DIRECTRICES CURRICULARES NACIONALES Y SUS REPERCUSIONES EN LOS CURRÍ- CULOS DE FORMACIÓN DE PROFESORES DE EDUCACIÓN FÍSICA
}

\section{RESUMEN}

Busco indagar de cuales modos las Directrices Curriculares Nacionales tienen repercutido en los currículos de formación de profesores de Educación Física para actuar en la Educación Básica, así como a (re) interpretación que el currículo hace de esas directrices. Problematiza la formación de profesores en el País y la formación en Educación Física, a partir de la legislación específica que reglamenta los cursos. Los análisis documentáis fueron realizadas en los currículos de formación de tres Instituciones de Enseñanza Superior (IES) e identificó tres formas substancialmente diferente de repercusión de las orientaciones legales.

Palabras clave: Educación Física; Formación Docente; Directrices Curriculares 